\title{
Obstructive Granulomatous Bronchiolitis Obliterans due to Mycobacterium tuberculosis
}

\author{
R. Agarwal11, V. Kumar², S.K. Jindal1
}

\begin{abstract}
Obstructive Granulomatous Bronchiolitis Obliterans due to Mycobacterium tuberculosis. R. Agarwal, V. Kumar, S.K. Jindal.

Bronchiolitis obliterans is an uncommon cause of obstructive airway disease in adults characterised by progressive irreversible airway obstruction. Granulomatous
\end{abstract}

bronchiolitis is a rare entity and tuberculosis presenting as bronchiolitis is distinctly uncommon. The authors present a case of tubercular granulomatous bronchiolitis obliterans, confirmed on histopathology, who responded completely to anti-tubercular chemotherapy.

Monaldi Arch Chest Dis 2005; 63: 2, 108-110.

Keywords: Bronchiolitis obliterans, granulomatous bronchiolitis, Mycobacterium tuberculosis.

${ }^{1}$ Department of Pulmonary Medicine

2 Department of Histopathology

Postgraduate Institute of Medical Education and Research, Chandigarh, India.

Correspondence: Dr. Ritesh Agarwal; Assistant Professor, Department of Pulmonary Medicine; Postgraduate Institute of Medical Education and Research, Chandigarh-160012, India; e-mail: drritesh1@ rediffmail.com

\section{Introduction}

Bronchiolitis obliterans is a term applied to processes that cause inflammation and fibrosis of the small airways without significant involvement of the interstitium. Granulomatous bronchiolitis is an uncommon cause of bronchiolitis. Pulmonary tuberculosis is the most common cause of granulomatous inflammation in India and manifests commonly as consolidation, nodules, masses, pleural effusion and airway involvement in form of atelectasis. Bronchiolocentric granulomas producing obstructive pulmonary dysfunction are rarely produced by Mycobacterium avium complex, but there are hardly any reports of similar presentation with Mycobacterium tuberculosis. We describe a case of biopsy-proven granulomatous bronchiolitis associated with obstructive airway defect which responded completely to anti-tubercular chemotherapy.

\section{Case report}

A previously healthy fifteen year old female presented with chief complaints of low-grade fever, progressively increasing dyspnea and dry cough of one year duration. She had loss of appetite and weight loss of $5 \mathrm{~kg}$ in the last 12 months. There was no history to suggest any collagen vascular disease. Physical examination revealed an emaciated female with a BMI of $16 \mathrm{~kg} / \mathrm{m}^{2}$. Her blood pressure was $110 / 70 \mathrm{mmHg}$, pulse $110 /$ minute and respirations $28 /$ minute. She had pallor and her respiratory system examination showed inspiratory crackles at both the lung bases. The remainder of the physical examination was unremarkable. Routine biochemical tests were normal, except for the presence of hypoalbuminemia. Complete blood count showed the presence of normocytic, normochromic anemia and raised erythrocyte sedimentation rate (52 $\mathrm{mm} /$ first hour). Blood and urine cultures were sterile. Serology performed for human immunodeficiency virus 1 and 2 was non-reactive. Arterial blood gases performed on room air revealed mild hypoxemia $\left(\mathrm{pH} 7.46, \mathrm{PaO}_{2} 70 \mathrm{~mm} \mathrm{Hg}, \mathrm{PaCO}_{2} 23\right.$ $\left.\mathrm{mmHg}, \mathrm{HCO}_{3} 23 \mathrm{mEq} / \mathrm{L}\right)$. Her chest radiograph was grossly normal (figure 1). Computed tomography showed bilateral mosaic attenuation with pres-

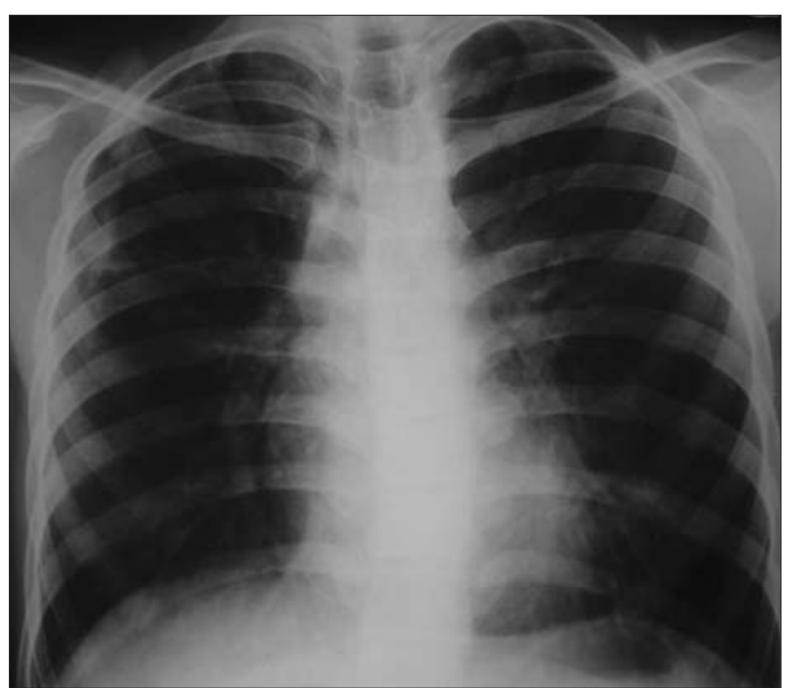

Fig. 1. - Chest radiograph which is grossly normal except bilateral increased reticular markings. 
ence of air trapping on expiratory maneuver (figure 2 \& 3). Spirometry showed severe obstruction with $\mathrm{a} \mathrm{FEV}_{1}$ of $1.02 \mathrm{~L}$ (35\% predicted) with no bronchodilator reversibility. Diffusion capacity for carbon monoxide was decreased (35\% predicted). A provisional diagnosis of bronchiolitis obliterans was made and a trial of glucocorticoid was planned. Transbronchial biopsy obtained with fiberoptic bronchoscopy was done which showed non-caseating granulomas (figure 4); Ziehl-Neelson stain for acid-fast bacilli was positive. A Tuberculin test performed with 5-tuberculin units was positive with an induration of $20 \mathrm{~mm}$. A provisional diagnosis of tubercular bronchiolitis obliterans was made and patient was started on isoniazid, rifampin, pyrazinamide and ethambutol. At the one month follow-up, the patient had gained five kilogrammes in weight and her dyspnea had improved significantly. At the end of six months, the patient was asymptomatic and repeat spirometry showed a $\mathrm{FEV}_{1}$ of $2.14 \mathrm{~L}$ with a normal diffusion capacity for carbon monoxide. The patient at one year follow-up is asymptomatic and doing well.

\section{Discussion}

Bronchiolitis Obliterans (BO) is inflammation characterised by obliteration of the bronchioles. When the cause of $\mathrm{BO}$ is not known, it is then referred to as idiopathic or cryptogenic. Patients usually present with persistent cough, worsening dyspnea and bibasilar inspiratory crackles. Pulmonary function tests show obstructive defect with no significant response to bronchodilators in majority of the patients. Diffusing capacity is commonly reduced. Chest radiography can be either normal or shows non-specific findings like hyperinflation, reticulonodular opacities and peripheral attenuation of the vascular markings. High-resolution computed tomography (HRCT) demonstrates multilobular areas of decreased attenuation and vascularity with evidence of air-trapping [2]. Although surgical lung biopsy is the gold standard for diagnosis, transbronchial lung biopsy is helpful in a minority of cases [1]. In most clinical settings, bronchiolitis obliterans is poorly responsive to corticosteroid therapy, tends to be progressive, resulting in respiratory failure and death [1].

The known causes of bronchiolitis obliterans include connective tissue disorders (most common), infections (viruses like adenovirus, respiratory syncytial virus, influenza, parainfluenza, and mycoplasma.), inhalational injury, drugs (gold, penicillamine), organ transplantation, and many others. The causes of granulomatous bronchiolitis are few and include rheumatoid arthritis, Wegener's granulomatosis, berryliosis, Crohn's disease and mycobacterial infections such as Mycobacterium avium complex.

Tuberculosis and other mycobacteria can involve the airways, but they mainly affect larger airways. Isolated involvement of small airways is not known. Mycobacteria are a very rare cause of granulomatous bronchiolitis. There are only three reported cases of mycobacterium avium complex causing granulomatous bronchiolitis [3-5]. All three patients were immunocompetent, had granulomas on histopathology,

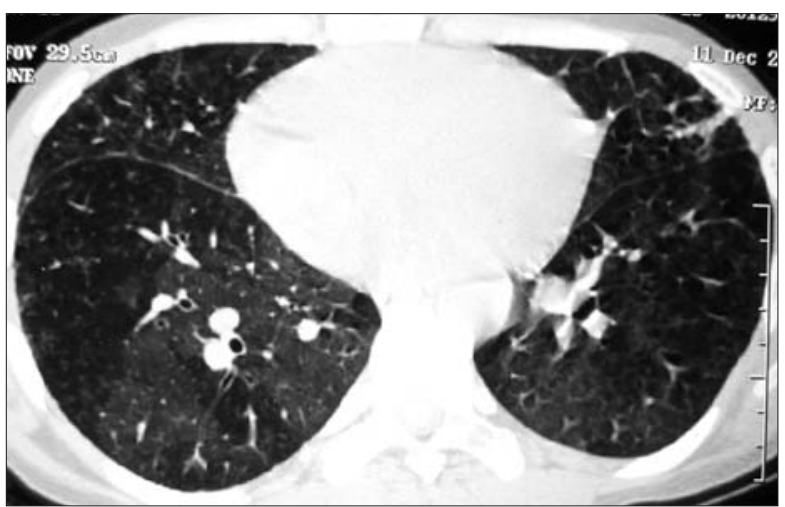

Fig. 2. - High-resolution computed tomography showing bilateral mosaic attenuation.

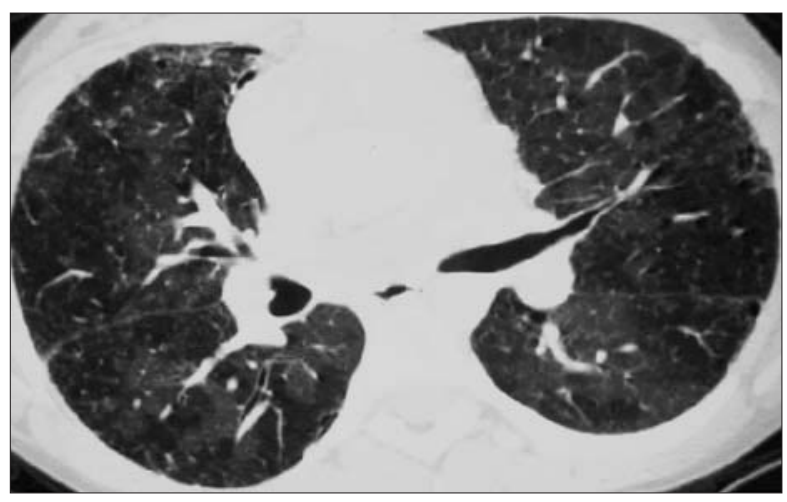

Fig. 3. - High-resolution computed tomography (expiratory views) demonstrating air-trapping.

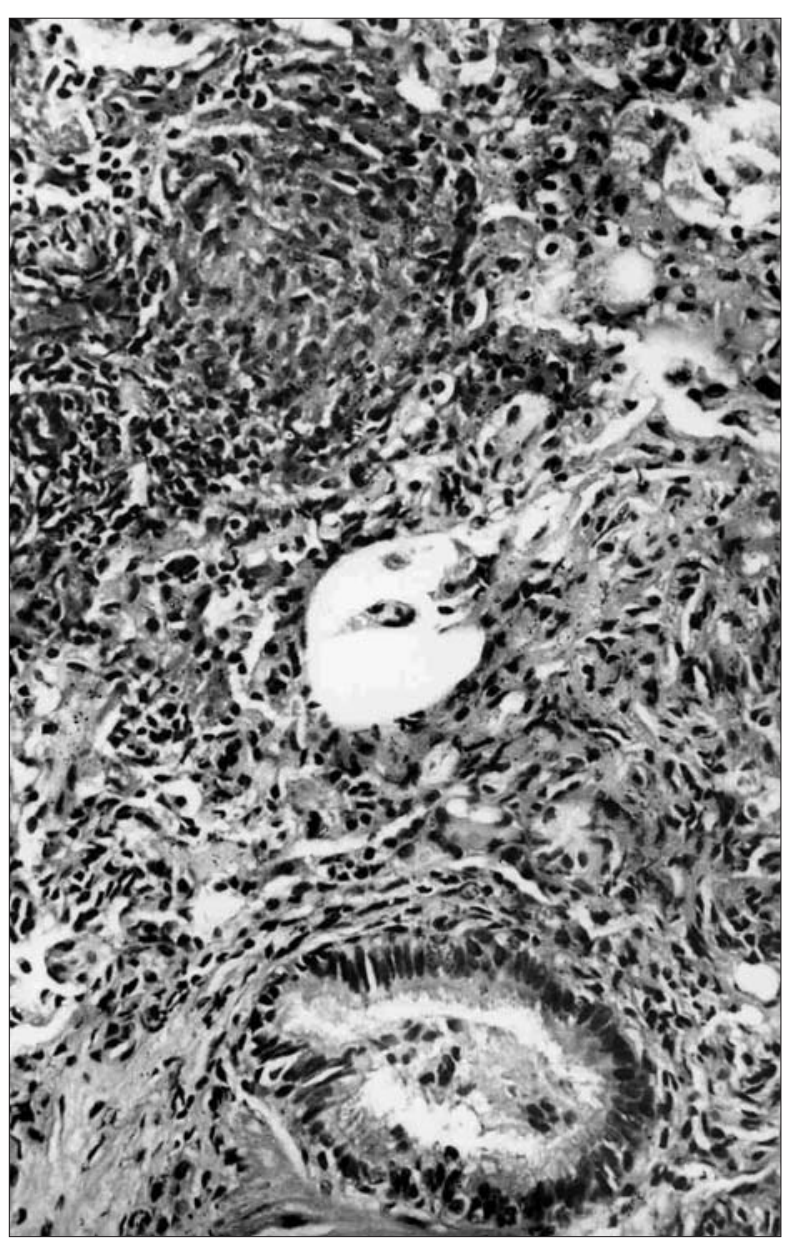

Fig. 4. - Photomicrograph showing peri-bronchiolar non-caseating epitheloid cell granulomas (x 260). 
Table 1. - Reported cases of mycobacterial bronchiolitis obliterans in English literature

\begin{tabular}{|c|c|c|c|c|c|}
\hline Author & Age/Sex & Clinical features & Treatment & PFT & TST \\
\hline $\begin{array}{l}\text { Murphy et al. } \\
\text { N Engl J Med, } 1996 \text { [4] }\end{array}$ & $40 \mathrm{yr} / \mathrm{M}$ & $\begin{array}{l}\text { Cough \& dyspnea } \\
-2 \text { months }\end{array}$ & $\begin{array}{l}\text { Ciprofloxacin } \\
\text { Clarithromycin } \\
\text { Rifampin }\end{array}$ & Obstructive & $-\mathrm{ve}$ \\
\hline $\begin{array}{l}\text { Kahana et al. } \\
\text { Chest, } 1997 \text { [5] }\end{array}$ & $20 \mathrm{yr} / \mathrm{F}$ & $\begin{array}{l}\text { Cough \& dyspnea } \\
-3 \text { months }\end{array}$ & $\begin{array}{l}\text { Ciprofloxacin } \\
\text { Clarithromycin } \\
\text { Rifampin } \\
\text { Ethambutol }\end{array}$ & Restrictive & $-\mathrm{ve}$ \\
\hline $\begin{array}{l}\text { Grimes et al. } \\
\text { Respiration, } 2001 \text { [3] }\end{array}$ & $44 \mathrm{yr} / \mathrm{M}$ & $\begin{array}{l}\text { Cough \& dyspnea } \\
-6 \text { months }\end{array}$ & $\begin{array}{l}\text { Ciprofloxacin } \\
\text { Clarithromycin } \\
\text { Clofazimine }\end{array}$ & Obstructive & $-\mathrm{ve}$ \\
\hline
\end{tabular}

PFT pulmonary function test, TST tuberculin skin test.

and responded well to chemotherapy (table 1). Mycobacterium tuberculosis can also possibly cause granulomatous $\mathrm{BO}$ by the same mechanisms as those of Mycobacterium avium complex. There is a single report of tuberculous $\mathrm{BO}$, in French literature, in a patient following lung transplantation [6].

The patient we report had all clinical features to suggest tuberculous granulomatous BO. She had no other symptom to suggest any other known cause of granulomatous BO, had definite HRCT evidence of bronchiolitis, obstructive defect on lung function tests, and granulomas on lung biopsy. Moreover the granulomas were positive for acid-fast bacilli, her tuberculin skin test was positive, and she showed subjective and objective response to antitubercular chemotherapy.

In conclusion, we report a rare presentation of tuberculosis as bronchiolitis obliterans. It is important to consider this etiology in the approach to bronchiolitis obliterans, as institution of glucocorticoid therapy without anti-tubercular therapy can be associated with adverse outcomes.

\section{References}

1. Ryu JH, Myers JL, Swensen SJ. Bronchiolar disorders. Am J Respir Crit Care Med 2003; 168: 1277-1292.

2. Desai SR, Hansell DM. Small airways disease: expiratory computed tomography comes of age. Clin Radiol 1997; 52: 332-337.

3. Murphy RLH, Merk EJ. Case records of the Massachusetts General Hospital. Weekly clinicopathological exercises. Case 6-1996. A 40-year-old man with a cough, increasing dyspnea, and bilateral nodular lung opacities. N Engl J Med 1996; 334: 521-526.

4. Kahana LM, Kay JM, Yakrus MA, Waserman S. Mycobacterium avium complex in an immunocompetent young adult related to hot tub exposure. Chest 1997; 111: 242-245.

5. Grimes MM, Cole TJ, Fowler AA 3rd. Obstructive granulomatous bronchiolitis due to Mycobacterium avium complex in an immunocompetent man. Respiration 2001; 68: 411-415.

6. Loire R, Brune J, Cordier JF, et al. A. Anatomical diversity of bronchiolitis obliterans after lung transplantation. Anatomical study of 16 cases among 64 transplantations. Arch Anat Cytol Pathol 1993; 41: 232-239.

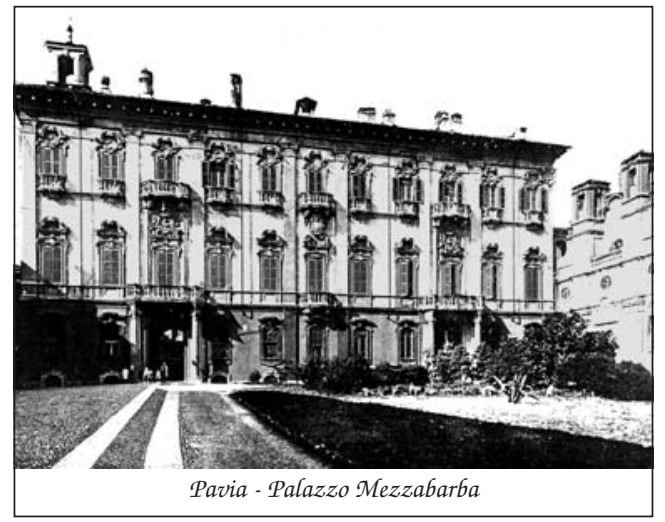

